\title{
A Desalambrar los caminos públicos para luchar contra la despoblación
}

\author{
Manuel Trujillo Carmona | Plataforma Ibérica por los Caminos Públicos \\ URL de la contribución <www.iaph.es/revistaph/index.php/revistaph/article/view/4419>
}

\section{RESUMEN}

Hay unos bienes públicos que son los grandes olvidados del territorio rural. Los caminos y vías pecuarias que fueron utilizados desde época ancestral para el paso de personas, caballerías y ganado, y que fueron después sustituidos en gran medida por las carreteras y carriles destinados al tránsito de vehículos. Desde hace unos años la demanda de espacios para el senderismo, ciclismo o la contemplación de la fauna ha hecho que haya un resurgir del interés por estos viejos caminos. Sin embargo, ha ocurrido un hecho que impide este aprovechamiento, al igual que el mantenimiento de los antiguos usos como el movimiento de ganado: miles de kilómetros de estos caminos son usurpados por fincas particulares, en especial por aquellas dedicadas a la caza. Las administraciones, ayuntamientos y comunidades autónomas son cómplices por omisión de este desfalco, y solo la voz de la ciudadanía se alza para la lucha contra esta injusticia. Se hace necesaria una pronta actuación de las administraciones para inventariar, recuperar y proteger estos caminos que muy a menudo son de gran interés desde el punto de vista histórico y patrimonial e imprescindibles para el desarrollo social y turístico de las zonas rurales de España, pudiendo así colaborar en la mitigación de la despoblación.

\section{Palabras clave}

Caminos públicos | Despoblación | Movilización ciudadana | Plataforma A Desalambrar | Plataforma Ibérica por los Caminos Públicos | Reivindicación | Trashumancia | Usurpación | Vías pecuarias | 


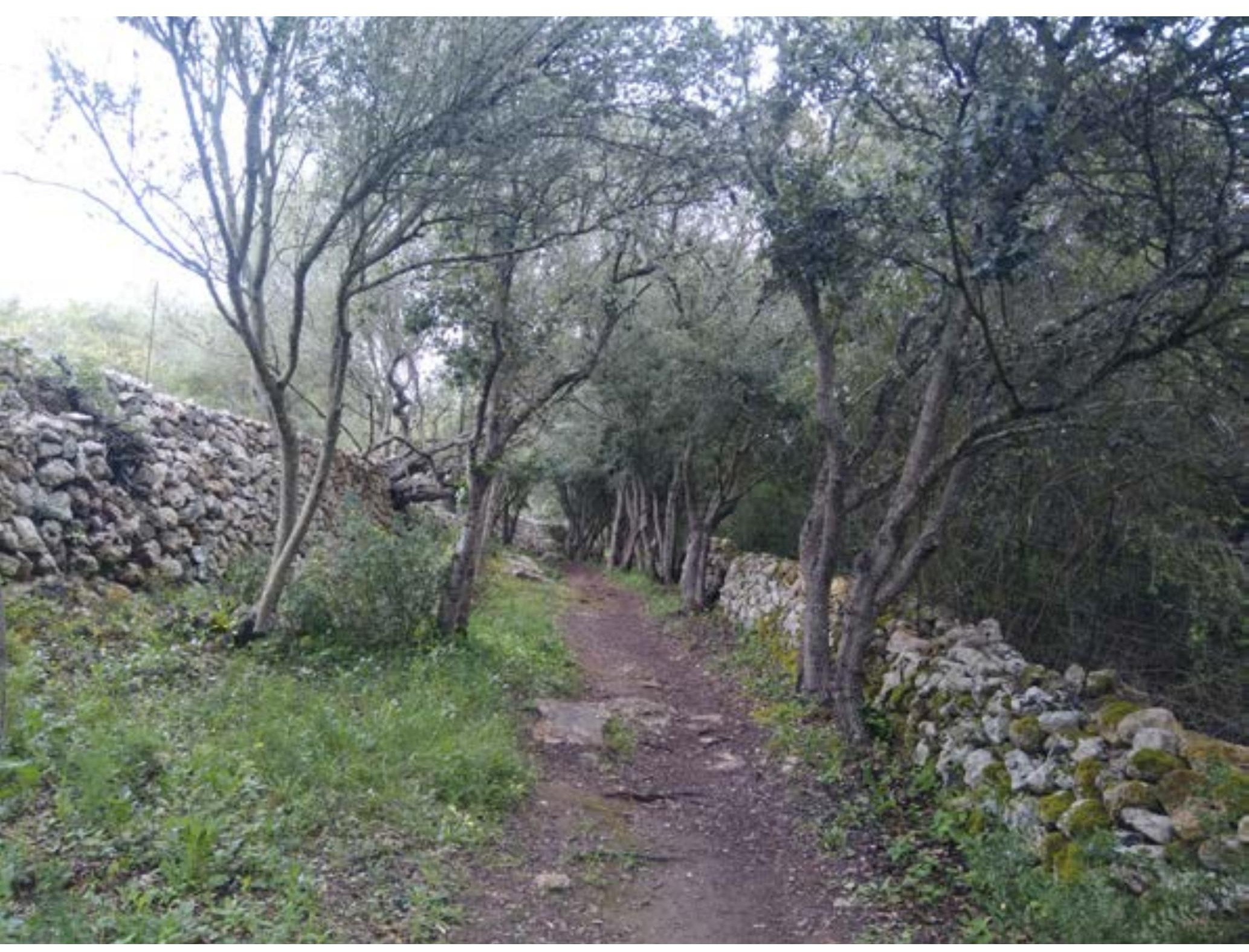

Cami Ral en Menorca, ejemplo de muros de piedra en seco, rehabilitado por los vecinos | foto Manuel Trujillo Carmona 
La red viaria en España tiene su primer gran desarrollo en época de la cultura romana. En los siglos siguientes esta red se va ampliando y se unen a estos caminos otros como las vías pecuarias, muchas veces coincidente con esos caminos romanos, y que desde la Edad Media goza de la protección real gracias a la importancia económica de la ganadería en esos tiempos. La llegada de las carreteras y los ferrocarriles va arrinconando estos caminos, de forma que poco a poco se deja de mover el ganado a pie, para transportarlo en camiones y trenes, e igualmente la mayor parte de los desplazamientos de personas se dejan de hacer a pie, en burro o a caballo para hacerse en coche. A lo largo del siglo XX la red de carreteras se amplía y ya llegan a casi todos sitios. El automóvil es el protagonista indiscutible de la movilidad. Incluso en las zonas rurales y agrícolas se construyen carriles que, sin ser carreteras, están diseñadas pensando en su uso para los coches.

Mientras se generalizan las carreteras y el uso del automóvil, va cayendo en desuso esa red de caminos y veredas. En algunos casos las carreteras se construyen sobre ellos, pero en muchos otros casos no, porque sus trazados a veces demasiado abruptos no eran adecuados para los automóviles. En muchos casos caen prácticamente en el olvido. A la vez, el campo se despuebla, y los terrenos de monte que anteriormente eran utilizados por la gente que habitaba en pueblos, aldeas o caseríos para cultivarlos, para tener el ganado o para recolectar leña, frutos $u$ otras tareas, dejan de utilizarse. Pasan a controlarse por la propiedad de las tierras, creándose a veces grandes latifundios, que solo los usan para el ocio personal o para la actividad cinegética. Se generaliza un hecho que antes era excepcional: el vallado de las fincas.

Se consolida así a finales del siglo XX y principios del XXI una privatización de hecho del uso de los terrenos forestales, que antes era prácticamente abierto a toda la población. En el cierre masivo de fincas los propietarios no ven en los caminos más que un estorbo. En unos casos, porque ya no se utilizan, no les prestan atención. En otros, el reciente auge de la utilización de los espacios naturales para el ocio, como el senderismo o el ciclismo, hace molesta la presencia de personas en las fincas, para evitar molestias a esa ganadería extensiva en que se ha convertido la actividad cinegética, o simplemente por desconfianza hacia los extraños.

Alguna gente se pregunta qué derecho hay a estos cierres. La memoria de algunas personas que recordaban los caminos que consideraban de todos y todas se aúna con las nuevas tecnologías y las redes sociales que permiten compartir la información y acceder a viejos mapas, llegándose a la conclusión de que es necesario detener y revertir esa tendencia destructiva de los caminos. Llega así la necesidad de mirar a la administración, cuyas viejas leyes, como el Código Civil, heredero del derecho romano, y también las nuevas, como la Ley de Vías Pecuarias promulgada oportunamente en 1995, obligan a proteger estos bienes, declarados de dominio público, y 
por tanto, imprescriptibles e inembargables. Por desgracia la administración también ha olvidado sus deberes, y lo más habitual es que ni siquiera tenga constancia de cuáles son sus caminos.

Van apareciendo en diversos puntos de nuestro territorio organizaciones que intentan hacer que se detenga el progresivo cierre de caminos y vías pecuarias, primero desde colectivos ecologistas y ganaderos, y después también por parte de senderistas y ciclistas. Muchos de estos colectivos y personas individuales conformarán a partir del año 2007 la Plataforma Ibérica por los Caminos Públicos.

\section{VÍAS PECUARIAS}

Las vías pecuarias son los itinerarios que ancestralmente han utilizado los ganaderos para desplazar al ganado, principalmente las ovejas merinas. Además de para el desplazamiento, también aprovechaban sus pastos. En el siglo XIII Alfonso X el Sabio creó el Honrado Concejo de la Mesta de los Pastores de Castilla. Ya en el siglo XV, con el aumento de los privilegios de la ganadería, el Libro de Leyes y privilegios de la Mesta -1489-, primero, y el Código de Malpartida -1492- después, vienen a organizar internamente la Mesta.

Tras diversas vicisitudes y cambios legislativos, en 1995 se promulga la Ley española de Vías Pecuarias, que declara que las competencias son autonómicas. A partir de esta fecha, en la mayoría de las comunidades autónomas se han ido publicado reglamentos o leyes propias sobre vías pecuarias.

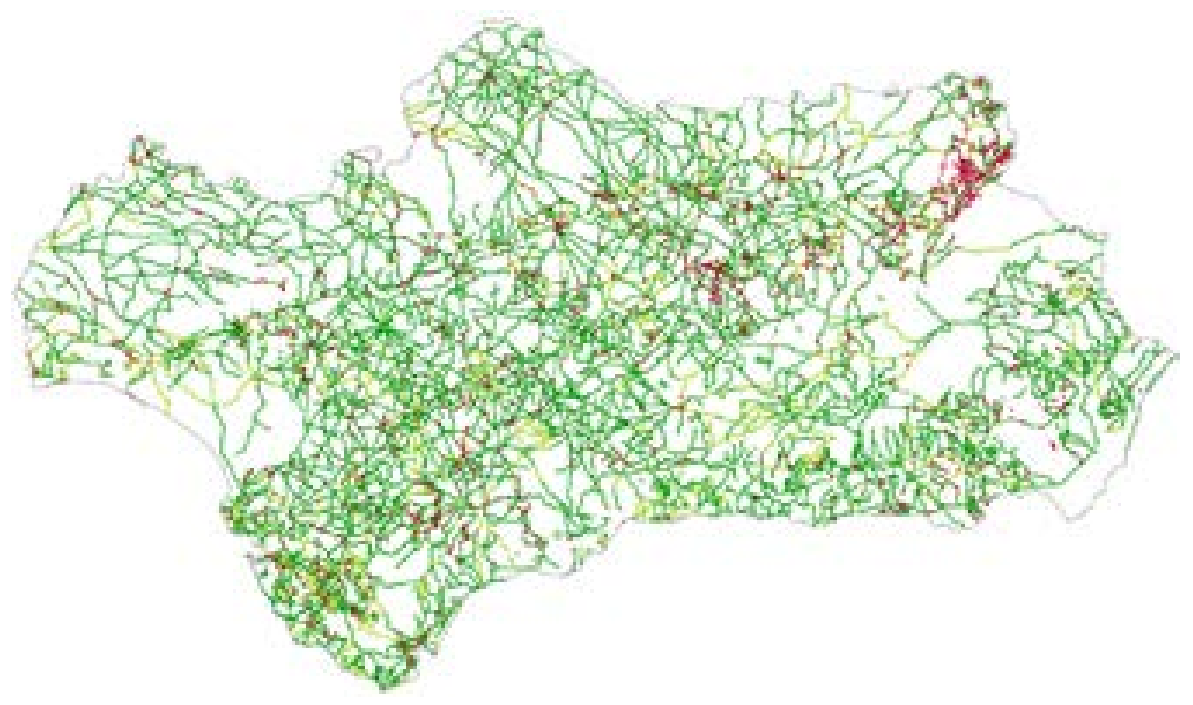


La Ley de Vías Pecuarias de 1995 declara las vías pecuarias como bienes de dominio público de las comunidades autónomas y, en consecuencia, inalienables, imprescriptibles e inembargables. Se consideran usos complementarios de las vías pecuarias el paseo, la práctica del senderismo, la cabalgada y otras formas de desplazamiento deportivo sobre vehículos no motorizados siempre que respeten la prioridad del tránsito ganadero.

Se estima que existen unos 125.000 km de vías pecuarias en España, aunque según la Fundación para la Ecología y la Protección del Medio Ambiente (VILLALVILLA, 2005), de los 125.000 km de vías pecuarias con los que contábamos tan sólo nos quedan hoy día 85.000 , habiéndose perdido ya 40.000 $\mathrm{km}(32 \%)$.

La situación de partida era distinta según las comunidades autónomas, ya que en algunas, como Andalucía o Madrid, casi todos los municipios tenían realizada la clasificación de vías pecuarias, en otras como Cataluña, La Rioja o Aragón tenían muy pocas clasificaciones hechas. En 2005, mientras

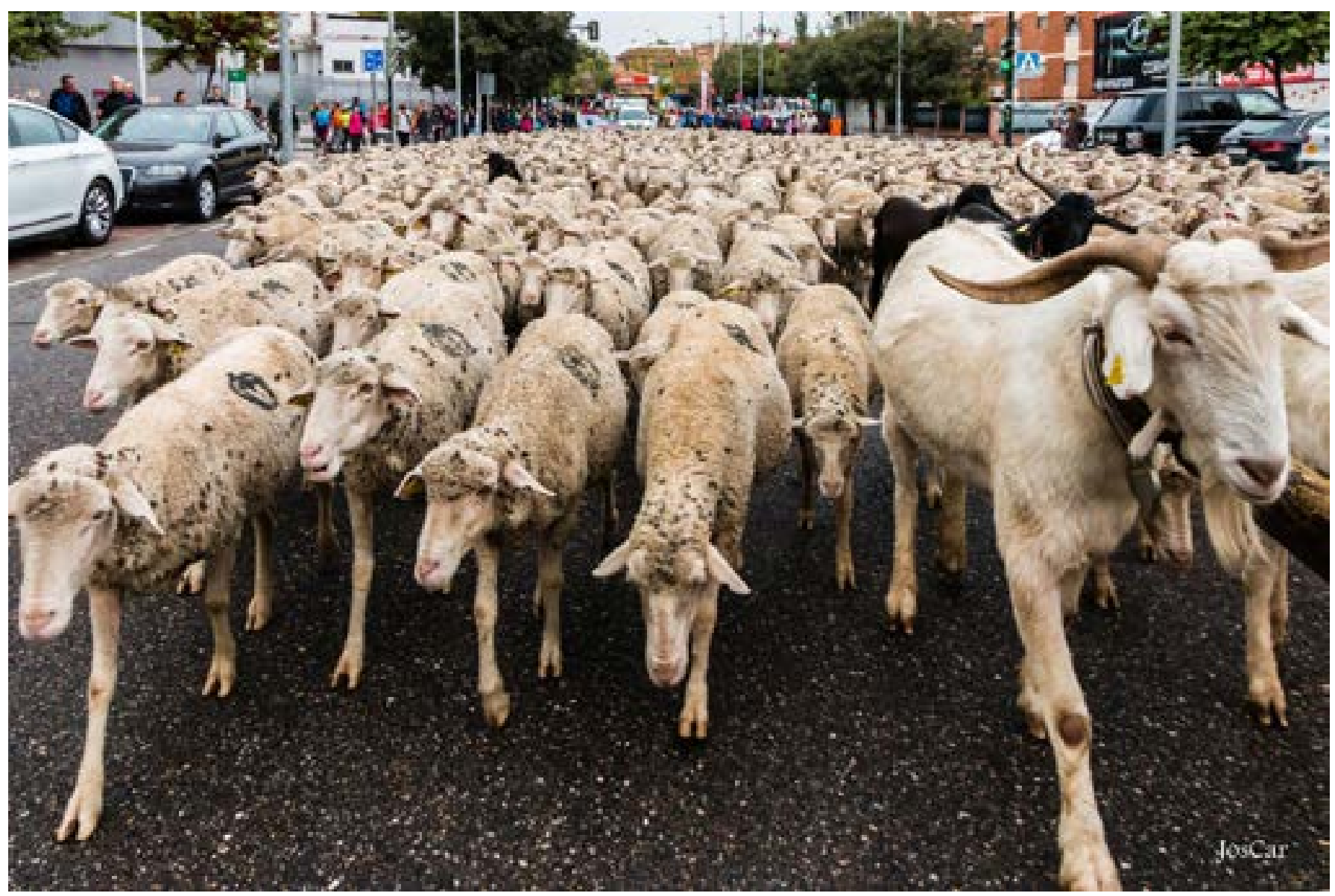


Andalucía y Extremadura habían avanzado bastante en la recuperación de las vías pecuarias, Castilla y León, Murcia, Catalunya y el País Valenciano eran las más atrasadas (VILLALVILLA, 2005). La Junta de Andalucía desde el año 2010 ha paralizado su programa de recuperación de las vías pecuarias, y en cambio Madrid y Castilla-La Mancha han avanzado notablemente colocándose detrás de Extremadura como comunidades con más deslindes.

Las vías pecuarias están en total desprotección hasta que se clasifican, y también en la práctica mientras que se deslindan ya que, al no tener certeza legal de su recorrido, cualquiera las usurpa y borra del terreno, sin que normalmente las administraciones públicas hagan nada para evitarlo. Son innumerables las denuncias de vías pecuarias usurpadas, en especial en Andalucía, sin que, por lo general, y a pesar de las denuncias correspondientes, la Junta de Andalucía actúe como debería ser su obligación.

Hay fuertes intereses en que las vías pecuarias desaparezcan y que estos terrenos públicos sean privatizados. Pero quienes hacen verdadera labor de lobby son los propietarios de fincas agrupados en la patronal ASAJA con una fuerte oposición tanto en el ámbito público como en el judicial. En el caso andaluz la hiperactividad administrativa y judicial de ASAJA y la pasividad andaluza ha hecho que la mayoría de los deslindes estén paralizados, y los recursos sin responder, muchos desde fechas tan lejanas como el año 2007.

\section{CAMINOS RURALES PÚBLICOS}

Los caminos rurales públicos son aquellos de titularidad y competencia municipal que facilitan la comunicación directa con pueblos limítrofes, con pequeños núcleos urbanos o con fincas, y que sirven a los fines de la agricultura y la ganadería (SERRANO FERRER, 2007). Los caminos públicos son bienes demaniales, inembargables, inalienables e imprescriptibles.

La normativa sobre caminos públicos es menos específica que la de vías pecuarias, ya que normalmente tenemos que remitirnos a la legislación general sobre bienes de las administraciones públicas, que son la Ley de Bases de Régimen Local de 1986 y la Ley del Patrimonio de las Administraciones Públicas, de 2003, que se refieren a los caminos como uno más de los bienes de la administración local.

En la Ley del Patrimonio de las Administraciones Públicas, de 2003, se especifica la obligación de las administraciones de tener un inventario de sus bienes, por tanto, también de los caminos, y de inscribirlos en el registro de la propiedad, igualmente la capacidad de investigar, deslindar, y recuperar los bienes. También es conveniente tener una ordenanza reguladora de su uso. 
Trabajos preparatorios para la primera edición del Mapa Topográfico Nacional (1872) donde aparecen los caminos públicos existentes en ese momento mapa Instituto Geográfico Nacional

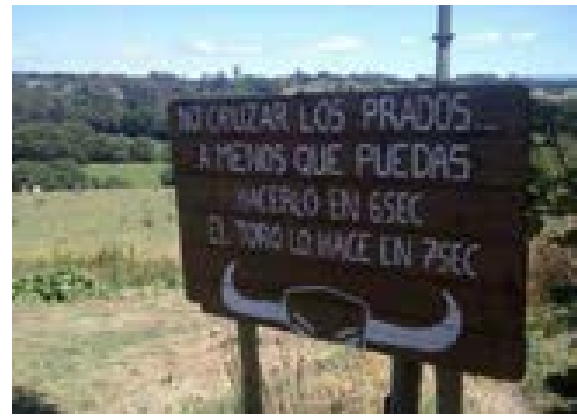

Cartel amenazando con la presencia de toros en la cañada real soriana en Hornachuelos | foto Manuel Fandinho

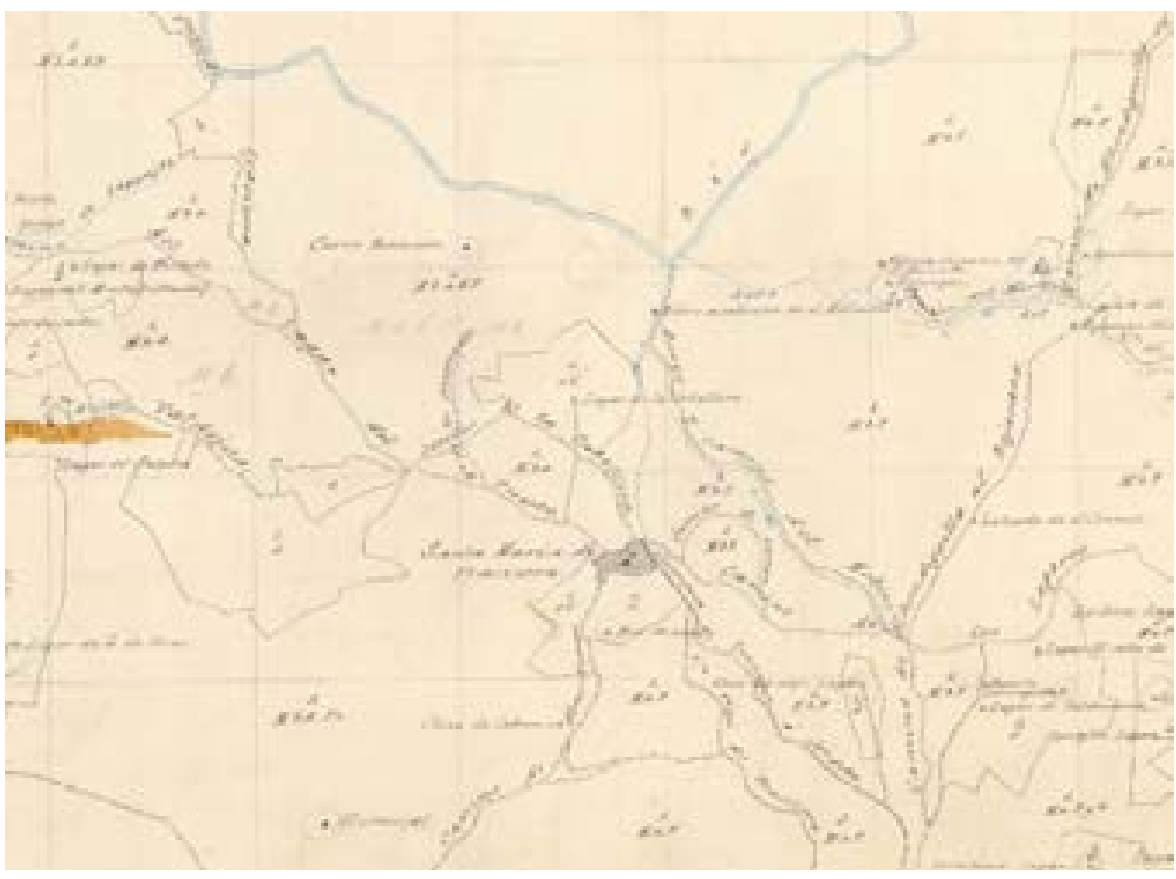

La cuantificación de los caminos municipales es muy complicada, dado que no existen inventarios de caminos generales. Sin embargo, por hacernos una idea de su dimensión, podemos señalar que en el caso de Extremadura, única comunidad autónoma donde se está elaborando un inventario general de caminos, cuando se llevan catalogados los caminos del $70 \%$ de los municipios, se han encontrado más de 67.000 kilómetros, lo que proporcionalmente nos llevaría a más de un millón de kilómetros de caminos en toda España.

Como hemos visto, los ayuntamientos tienen el deber de tener inventariados los caminos y conservarlos debidamente para su uso. Es difícil realizar una investigación rigurosa de en qué medida esta obligación se cumple, ya que la cantidad de ayuntamientos existente y la falta de estadísticas en la materia van a dificultar enormemente este trabajo. Aunque cada vez más ayuntamientos están realizando su inventario de caminos, todavía son muy minoritarios, estimándose en menos del $10 \%$ los ayuntamientos que lo tienen aprobado. Ante esa falta de actuación, en determinadas zonas, como Sierra Morena, la cantidad de caminos que se podrían estar perdiendo puede ser del $80 \%$.

Recientemente se ha aprobado la Ley de caminos públicos y rutas senderistas de Mallorca y Menorca, que se une a Extremadura como los dos únicos territorios que tienen una legislación propia sobre caminos, que promueve la realización de los inventarios y garantiza medidas para evitar el cierre de 
caminos. $\mathrm{O}$ al menos facilita herramientas para impedirlos en caso de que los responsables no actúen.

\section{Usurpación de los caminos públicos}

Aquí no se cuentan por casos aislados, sino que en determinadas zonas son mayoritarios los caminos usurpados. En inventarios comarcales, como el de Sierra Morena cordobesa, se puede ver que cerca del $80 \%$ de los caminos están usurpados en alguna medida por la propiedad.

Situaciones extremas son las apropiaciones de aldeas enteras, como por ejemplo: Fuente Humorera en Burgos, Villaescusa de Palositos en Guadalajara, Huércemes en Cuenca, Otínar en Jaén. En estos casos los propietarios de las fincas no es que no respeten los caminos, es que se apropian de calles, cementerios, fuentes, iglesias, y también de las propiedades particulares que no se hayan vendido. La causa de esta falta de protección hacia los caminos puede ser doble: por un lado, a menudo a los ayuntamientos les puede resultar costosa la labor de recuperar los caminos, con los posibles recursos de los propietarios. Por otro lado, a menudo la propiedad la ostentan personas muy influyentes, y los ayuntamientos temen indisponerse con ellos.

Los caminos públicos no solo son un bien a defender por su necesidad para la circulación de las personas. Además de ello son un bien patrimonial histórico, que habría que defender como tal. Ya se ha hablado de la larguísima historia de las vías pecuarias, asociada a la trashumancia, que ha sido declarada manifestación representativa del patrimonio cultural inmaterial, y que está propuesta para ser declarada como patrimonio cultural inmaterial de la humanidad por la UNESCO. Además no sólo son las veredas, sino también los descansaderos, abrevaderos, contaderos, puentes, etc., es decir, un vasto patrimonio material que debería protegerse.

Más larga aún es la historia de otros muchos caminos. Hay muchísimas calzadas y puentes de época romana y árabe, pero sin irnos más lejos, el grueso de caminos públicos de los que tenemos documentación se remontan al menos al siglo XIX, si no a tiempos anteriores, y son una muestra de tecnologías concretas que se utilizaban para resolver los problemas. Algunos caminos se han declarado BIC, pero en realidad serían muchísimos los que merecerían esa calidad. Y no solo los caminos, también infraestructuras asociadas, como puentes o fuentes. Un ejemplo es la arquitectura de la piedra en seco, declarada también como patrimonio inmaterial de la humanidad por la UNESCO, y es la técnica con la que se han construido multitud de caminos y otros elementos como muros y paredes, que están deteriorándose de forma masiva, y la protección del hecho inmaterial debería también ser una garantía para su protección material. Tenemos el ejemplo de lugares como 


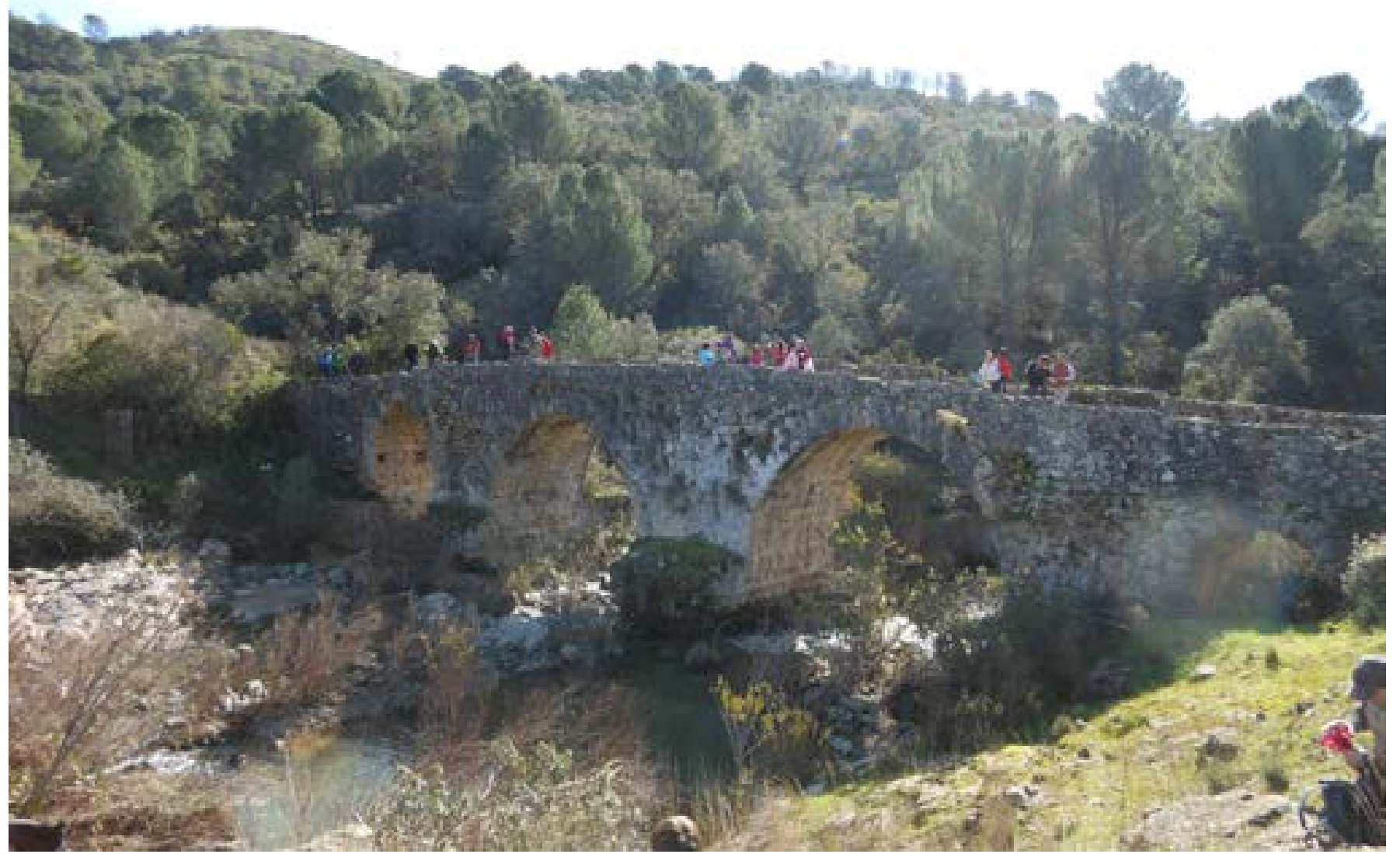

Puente de origen romano en la vereda del Pretorio (Córdoba) | foto Plataforma A Desalambrar

las Islas Baleares y Cataluña donde se están llevando a cabo programas de rehabilitación de estos elementos, que pueden ser además una fuente de trabajo e ingresos para las zonas rurales.

\section{Los caminos públicos como ayuda para evitar la despoblación}

Ya no es una novedad que las zonas rurales no pueden limitarse a las actividades productivas, y si hace unos años eran solo unas comarcas las que buscaban su prosperidad en el turismo rural, hoy casi todos los municipios de España buscan complementar su actividad con el mismo, que en muchos casos se convierte en su principal actividad. En los últimos años se vive un gran aumento en la práctica de los deportes al aire libre. Por ejemplo, las licencias federativas de ciclismo se duplicaron entre 2001 y 2018: pasando de 31.000 a 74.000, estando además cada vez más orientado a la montaña 
que a la carretera. Las licencias de montaña casi se cuadriplicaron: pasan de 65.000 en el 2001 a 237.000 en el 2018 (ANUARIO, 2018). Teniendo en cuenta que según las estimaciones disponibles (ANÁLISIS, 2018) solo el $21 \%$ de las personas que visitan los espacios naturales están federados, obtendríamos una cifra cinco veces mayor, es decir, más de un millón y medio de personas que practican un ocio para el que son necesarios los caminos.

Hay otras fuentes: en la encuesta sobre hábitos deportivos del Centro de Investigaciones Sociológicas-Consejo Superior de Deportes. Marzo-abril 2005 (MOSCOSO, 2008), el porcentaje de personas que practican el senderismo es el 4,5\% de las personas encuestadas. Esto supone 1.616 .752 personas, cifra muy parecida a la anterior. De ellos aproximadamente el 35\% lo practican al menos una vez por semana, y algo más de un $10 \%$ solo en vacaciones. También se pregunta en la encuesta si la persona, aunque actualmente no practique el senderismo, lo practicaría de existir un lugar adecuado para hacerlo en su entorno. A esta pregunta contestan afirmativamente en Castilla y León el $60 \%$ de los entrevistados, que representan a 1.185.000 personas, y en Madrid un 75\%, que representan a 3.700.000 personas (CIRIA; MOREIRA; RODRÍGUEZ, 2008).

Ante la problemática analizada, planteamos como posibles soluciones:

1. Elaboración de leyes de caminos nacional o autonómicas que establezcan las bases para su adecuada gestión y protección, y sirva como norma básica que informe a las correspondientes Ordenanzas Reguladoras Municipales de Caminos y Servidumbres públicas.

2. Elaboración o actualización por las comunidades autónomas de los inventarios municipales, al igual que se ha hecho en Extremadura, lo que garantiza unos mismos criterios para todos.

3. Concesión de fondos autonómicos para los deslindes, recuperación e inscripción en el registro de la propiedad de los caminos.

4. Protección de los caminos como bienes del patrimonio histórico y asignación de recursos para la rehabilitación de los caminos y sus elementos anexos.

\section{LA PLATAFORMA A DESALAMBRAR Y LA PLATAFORMA IBÉRICA POR LOS CAMINOS PÚBLICOS}

Ante la pasividad, cuando no complicidad, de las instituciones, la ciudadanía puede jugar un importante papel, denunciando los hechos, instando a 
Cancela que cierra la cañada real de los Potros (Lugros, Granada) en una marcha reivindicativa de la PICP | foto Plataforma Ibérica por los Caminos Públicos

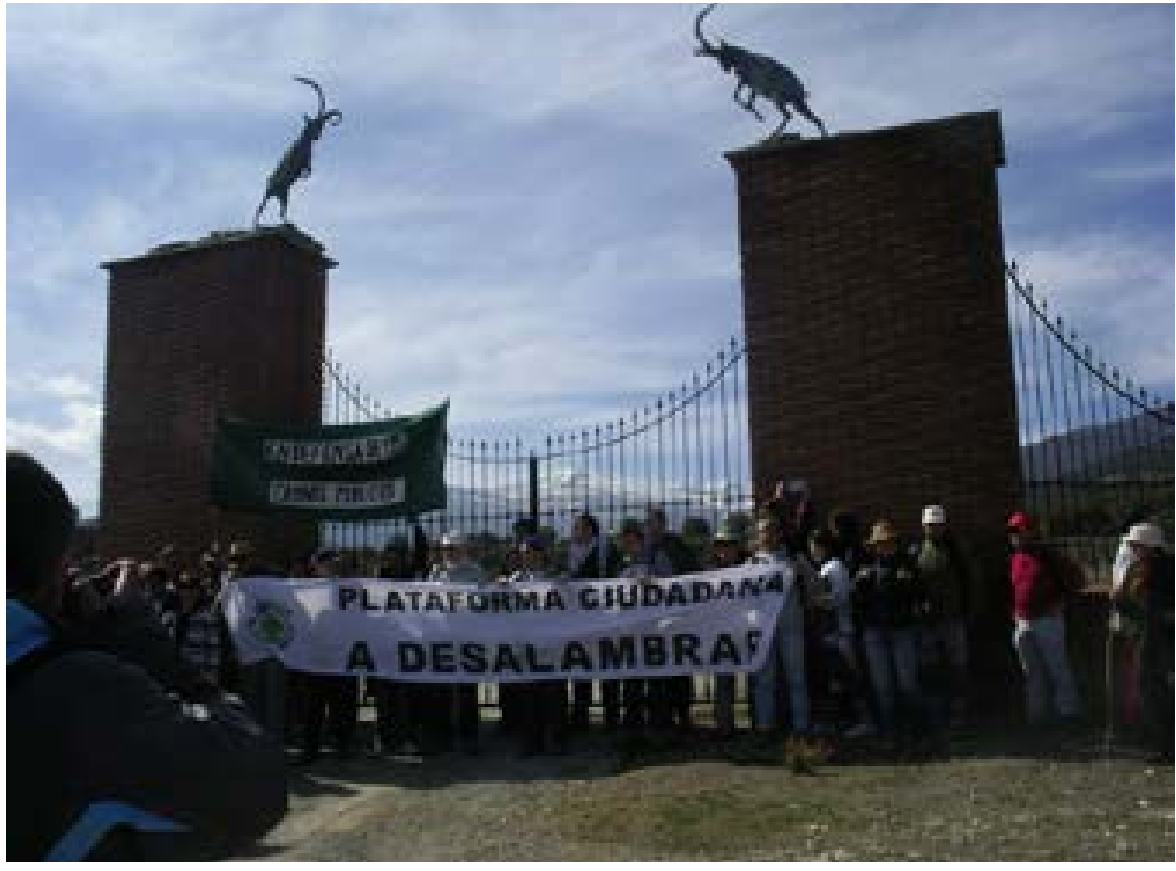

las administraciones a cumplir con sus deberes, difundiendo en la prensa los cierres de caminos, e incorporándose a asociaciones para denunciar los cierres con más efectividad. Finalmente, la vía judicial parece ser la última a la que hay que acudir si el resto fallan.

En las últimas décadas del siglo XX comienza a haber organizaciones que protestan por el cierre de caminos y veredas, sobre todo desde el movimiento ecologistas, por ejemplo en Ciudad Real o también sonadas fueron las denuncias del cantaor flamenco El Cabrero, que llegaron al Parlamento.

Ya en 2001 se crea la Plataforma A Desalambrar en Córdoba, primer grupo específicamente dedicado a la defensa de los caminos públicos, ante el cierre masivo que se estaba produciendo de los caminos y veredas que tradicionalmente se utilizaban, y agrupando a senderistas, ecologistas y ciclistas. En estos 18 años de vida, la Plataforma A Desalambrar ha pasado por muchas vicisitudes. En los primeros años, cuando Internet era aún una herramienta que comenzaba, había mucha falta de información sobre cuál era realmente la normativa sobre caminos públicos, y también era difícil encontrar documentación. Los mapas antiguos, en papel, se transmitían como un tesoro que se pasaba de mano en mano, sin realmente entender el significado que tenían. La bisoñez y el idealismo marcaban las actuaciones, lo que nos llevó incluso a tener que afrontar algunos juicios por romper candados, y reconocer el hecho ante jueces que anteponían los daños realizados al hecho de que el camino fuera público o no. Igualmente vimos 
cómo imponían a compañeros sanciones desmesuradas, de miles de euros, sin justificación alguna, y que aún hipotecan a algunas personas absolutamente inocentes.

Más adelante el incremento de la información en Internet, la colaboración con otras asociaciones y las redes sociales cambió totalmente la capacidad de informarse y formarse, generando un conocimiento y un corpus común de experiencias que hace que otras asociaciones que ahora se incorporan ya tengan mucho terreno avanzado.

La relación con las administraciones siempre ha sido de amor-desamor. Colaborando en todo lo posible, ayudando en lo que nos dejan, formando parte de Juntas Rectoras y del Consejo de Medio Ambiente. Pero a la vez, una crítica constante por el desinterés y nula resolución de los problemas de la administración, que se resume en que en 18 años el Ayuntamiento de Córdoba no ha sido capaz de abrir ni un solo camino de los que nos encontrábamos cerrados cuando la Plataforma A Desalambrar comenzaba.

Si bien en un primer momento el problema de los cierres parecía circunscribirse a Sierra Morena, poco a poco continúa la tendencia del cierre de fincas, y de los caminos que las atraviesan, en toda España. Así se organizan grupos en lugares tan diversos como Madrid, Segovia, Aragón, Murcia o Valencia. Especial mención habría que hacer a Mallorca, lugar donde se libra una lucha sin cuartel en todos los ayuntamientos entre propietarios usurpadores y muchas organizaciones de la sociedad civil, culturales, políticas, ecologistas, ecuestres, ciclistas, senderistas, que quieren recuperar los caminos.

En el año 2007 se crea la Plataforma Ibérica por los Caminos Públicos (PICP), que desde entonces coordina la actividad de estos grupos y da asesoramiento a asociaciones y particulares sobre cómo resolver sus problemas con los caminos. Entendemos que la situación de los caminos es similar, de forma generalizada, en casi toda España, aunque con matices importantes. La problemática con los cotos de caza es compartida en todas las zonas con ese tipo de explotación, cada vez más usual. En algunos territorios, como Madrid o la Comunidad Valenciana, es también importante el problema derivado de la construcción desaforada de urbanizaciones e infraestructuras. En Castilla y León y parte de Castilla-La Mancha la preocupación principal es precisamente el tema de este monográfico: la despoblación y la falta de personas que puedan dar vida y mantener los caminos.

La PICP organiza también unas jornadas anuales en defensa de los caminos, cada año en una localidad distinta de España. En noviembre de 2019 se celebra la 13. ${ }^{\text {a }}$ edición en Toledo. En estos momentos la componen 25 asociaciones de 16 provincias distintas. 


\section{CONCLUSIONES}

A pesar de que cada vez aumenta más el interés por disfrutar de la naturaleza y que, dado que gran parte de la superficie española es privada, el principal espacio que se puede utilizar son los caminos, los problemas debidos a la apropiación o el abandono de los mismos no cesan de crecer.

Se constata que las administraciones autonómicas y locales no hacen lo suficiente para proteger los bienes públicos de los que son titulares, dejando en la indefensión a los que quieren utilizarlos, y la movilización ciudadana, aunque cada vez más frecuente, no es suficiente.

Se requeriría un cambio normativo y una mayor concienciación de las administraciones que aumentara la protección de los caminos como herencia histórica y condición necesaria para la promoción económica, medioambiental, y de salud de nuestros pueblos y ciudades. 


\section{BIBLIOGRAFÍA}

- ANÁLISIS del perfil de los usuarios-visitantes del medio natural en España 2017-2018 (2018) [en línea] FEDME, 2018 <http://www.fedamon.com/attachments/article/2721/ EstudioVisitantesEspaciosNaturalesEspa\%C3\%B1a.pdf> [Consulta: 24/05/2019]

- ANUARIO de Estadísticas Deportivas 2018 (2018) [en línea] Madrid: Ministerio de Educación, Cultura y Deporte, Secretaría General Técnica, Subdirección General de Documentación y Publicaciones 2018. Disponible en línea: <http://www.culturaydeporte.gob.es/servicios-alciudadano-mecd/dms/mecd/servicios-al-ciudadano-mecd/ estadisticas/deporte/anuario-deporte/AED-2018/Anuario de_Estadisticas_Deportivas_2018.pdf $>$ [Consulta: 24/05/2 $\overline{0}$ 19]

- CIRIA NAVAS, R.; MOREIRA GREGORI, P. (2008) La práctica deportiva entre los turistas españoles. En Deporte, salud y medioambiente para una sociedad sostenible. $X$ Congreso AEISAD 2008. Madrid: Librerías Deportivas Esteban Sanz S. L., 2008 (Investigación Social y Deporte; n. ${ }^{\circ}$ )

- MOSCOSO SÁNCHEZ, D. (2008) Hábitos, actitudes y perfil sociodemográfico de los senderistas en España. Seminario Internacional sobre Senderismo y Territorio en Europa. En Seminario Internacional sobre Senderismo y Territorioen Europa. Málaga, 5al7dejulio de2008. Instituto de Estudios Avanzados, Consejo Superior de Investigaciones Científicas. Disponible en línea: <https://www.adesalambrar. com/documentos/habitos\%20actitudes\%20y\%20perfil\%20 sociodemografico $\% 20$ de $\% 20$ los $\% 20$ senderistas $\% 20$ en\%20espa\%C3\%B1a.pdf> [Consulta: 26/07/2019]

- SERRANO FERRER, M. E. (2007) Los caminos públicos municipales. Blog de Espúblico [en línea] 22 de marzo de 2007 <https://www.administracionpublica.com/ los-caminos-publicos-municipales/> [Consulta: 24/05/2019]

- VILLALVILLA ASENJO, H. (2005) Las vías pecuarias. Un balance de su situación en el Estado español. El Ecologista, n. ${ }^{\circ} 43,2005$ 